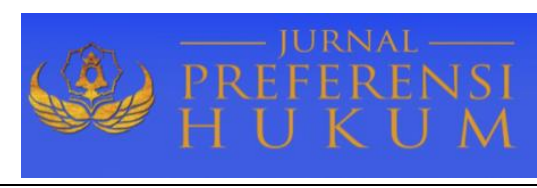

Jurnal Preferensi Hukum | ISSN: XXXX | E-ISSN: XXXX

Vol. 1, No. 2 - September 2020, Hal. 111-115| Available Online at https://www.ejournal.warmadewa.ac.id/index.php/juprehum

DOI: http://doi.org/10.22225/jph.v1i2.2394.111-115

\title{
KEWENANGAN PEMERINTAH KABUPATEN GIANYAR DALAM PENGATURAN ADMINISTRASI PENDUDUK PENDATANG
}

\author{
Bayu Angga Saputra, I Nyoman Putu Budiarta, I Nyoman Sujana \\ Fakultas Hukum Universitas Warmadewa, Denpasar-Bali, Indonesia
}

\begin{abstract}
Abstrak
Peningkatan jumlah pendatang di Gianyar dari tahun ke tahun selalu menunjukkan peningkatan sehingga berdampak seperti pada ketertiban, ketentraman dan keamanan masyarakat dan hingga saat ini belum ada landasan hukum yang melarang pendatang untuk berkunjung ke Bali pada umumnya dan Gianyar pada khususnya. Dengan demikian, terdapat kekosongan norma, yakni belum adanya aturan yang dapat dijadikan dasar hukum bagi melarang pengunjung ke Bali. Pemerintah Daerah Provinsi Bali mengambil langkah-langkah penataan dan penertiban pendatang melalui kebijakan pendaftaran pendatang dengan Surat Gubernur No. 470/7587/B.Tapem tentang Pedoman Pendaftaran Pendatang. Penelitian ini bertujuan untuk mengungkap kewenangan Pemerintah Daerah Gianyar dalam menyelenggarakan tertib administrasi kependudukan migran di Kabupaten Gianyar dan untuk mencari tahu sanksi yang dijatuhkan kepada pendatang yang tidak melaksanakan tertib administrasi di daerah tersebut. Jenis penelitian ini adalah penelitisn yuridis empiris karena penelitian ini menggunakan data atau fakta di lapangan yang ditinjau berdasarkan peraturan perundang-undangan terkait. Hasil penelitian ini menunjukkan bahwa Kabupaten Gianyar memiliki kewenangan dalam penyelenggaraan tertib administrasi penduduk bagi pendatang di Kabupaten Gianyar. Hal ini terlihat dari ketentuan dalam Peraturan Daerah Kabupaten Gianyar Nomor 1 Tahun 2002, dalam Pasal 2 yang berbunyi "setiap perpindahan penduduk, pekerjaan sementara dan penduduk musiman wajib terdaftar di Kepala Desa setempat." Kemudian, sanksi administratif yang diberikan kepada warga pendatang, yang tidak membuat KTP atau KIPEM lebih dari 3 bulan, ialah tidak diberikan pelayanan administrasi selamanya sehingga tidak dapat menetap secara permanen atau sementara di Kabupaten Gianyar.
\end{abstract}

Kata Kunci: Kewenangan; Penataan; Penduduk Migran

\begin{abstract}
The increase in the number of immigrants in Gianyar from year to year has always shown an increase that it has an impact on public order, tranquility and security and until now there is no legal basis that prohibits migrants from visiting Bali in general and Gianyar in particular. Thus, there is a norm vacuum, namely the absence of rules that can be used as a legal basis for prohibiting visitors to Bali. The Provincial Government of Bali takes steps to organize and control newcomers through a newcomer registration policy with a Governor's Letter No. 470/7587 / B.Tapem regarding Guidelines for Entrant Registration. This study aims to reveal the authority of the Gianyar Regional Government in carrying out an orderly administration of migrant population in Gianyar Regency and to find out the sanctions imposed on immigrants who do not carry out an orderly administration in the area. This type of research is empirical juridical research because this research uses data or facts in the field that are reviewed based on the relevant laws and regulations. The results of this study indicate that the Gianyar Regency has the authority to carry out an orderly population administration for immigrants in Gianyar Regency. This can be seen from the provisions in the Gianyar Regency Regional Regulation Number 1 of 2002, in Article 2 which reads "every movement of population, temporary work and seasonal residents must be registered with the local Village Head." Then, the administrative sanction given to immigrants, who do not make a KTP or KIPEM for more than 3 months, are they are not permitted to receive administrative services for the rest of their stay so that they cannot stay permanently or temporarily in in the region.
\end{abstract}

Keywords: Authority, Management; Migrant Population 


\section{Pendahuluan}

Dengan berubahnya tingkat kemakmuran lokal akan berpengaruh terhadap pola tingkah laku dimana masyarakat iokal enggan bekerja pada pekerjaan kasar seperti buruh bangunan, buruh disektor pertanian, perdagangan dan bahkan pekerjaan yang mengandung unsur religius (menjual canang) sudah dirambah oleh migran (Prayuginingsih et al., 2011). Kebutuhan kebutuhan masyarakat lokal sudah sebagian besar didatangkan dari jawa seperti kebutuhan upacara, demikian juga dengan produk souvenir antara lain : patung asmat, patung jerapah dan berbagai produk telah menghiasi toko kerajinan di Bali, sehinggan Bali disebut Big Market dengan modal keuletan, ketekunan dan kerja keras serta mempu membentuk jaringan kerja (network) rata rata kaum migran berhasil dafam usahanya.

Mengingat semakin banyaknya penduduk pendatang dari tahun ke tahun selalu menunjukkan peningkatan sehingga menimbulkan dampak seperti ketertiban, ketentraman dan keamanan masyarakat (Lumi, 2015), dan sampai saat ini tidak ada dasar hukum untuk melarang migran untuk datang ke Bali dan Gianyar khususnya, dalam hal ini ada norma kosong yakni belum adanya aturan yang dapat dipakai sebagai dasar hukum untuk melarang orang masuk ke Bali, maka pemerintah daerah Provinsi Bali mengambil langkah penataan dan penertiban penduduk pendatang melalui kebijakan pendaftaran penduduk pendatang (Larantika, 2017) di Provinsi Bali dengan Surat Gubemur No. 470/7587/B. Tapem tentang pedoman pendaftaran penduduk pendatang. Berdasarkan Pasal 1 Surat Edaran Gubernur Bali No 470/7587/B.Tapem, Tanggal 14 Nopember 2002, penduduk pendatang adalah penduduk yang datang akibat mutasi kepindahan antar Kabupaten/Kota / Provinsi Bali, yang akhirnya pedoman tersebut ditindak lanjuti dengan Kesepakatan Bersama Gubernur Bali dengan Bupati/Walikota se-Provinsi Bali dengan No:153 tahun 2003 Tentang Pelaksanaan Tertib Administrasi Kependudukan di Provinsi Bali, bersepakat melaksanakan kesepakatan bersama mengenai tertib administrasi kependudukan di masing masing Kabupaten/Kota dalam wilayah Provinsi Bali.

Berdasarkan Kesepakatan Bersama Gubemur Ball dengan Bupati/Walikota Se-Bali No 153 Tahun 2003 Tentang Pelaksanaan Tertib Administrasi Kependudukan di Provinsi Bali, jenis penduduk pendatang dibedakan menjadi penduduk pendatang tinggal sementara dan penduduk pendatang tinggal menetap, yang dijelaskan sebagai berikut: yaitu Pasal 1 huruf (b), penduduk pendatang tinggal sementara adaiah Warga Negara Indonesia yang tinggal di luar domisili asli/tempat tinggal tetapnya dengan Kartu Identitas Penduduk Sementara (KIPS) / Surat Tanda Pendaftaran Penduduk Tinggal Sementara (STPPTS). Selanjutnya, Pasal 1 huruf (c), penduduk pendatang tinggal menetap terdiri atas: Pendatang dengan mempunyai pekerjaan tetap, Pendatang yang mempunyai tempat tinggal tetap, dan Mutasi/perpindahan TNI/Polri, PNS, mahasiswa dan pelajar.

Dari pedoman/petunjuk diatas, di Kabupaten Gianyar dikeluarkan Keputusan Bupati Gianyar No 180 Tahun 2002 tentang Pendaftaran Penduduk Pendatang di Kabupaten Gianyar, dimana setiap perpindahan penduduk, penduduk semantara dan penduduk musiman wajib didaftarkan kepada Kepala Desa/Kelurahan setempat sesuai Pasal 2 Keputusan Bupati Gianyar No 180 Tahun 2002.

Berdasarkan latar belakang tersebut diatas, maka penelitian ini bertujuan untuk mengetahui kewenangan Pemerintah Daerah Gianyar dalam melakukan tertib administrasi terhadap penduduk pendatang di Kabupaten Gianyar, dan untuk mengetahui sanksi yang diberikan terhadap penduduk pendatang yang tidak melakukan tertib administrasi di Kabupaten Gianyar.

\section{METODE PENELITIAN}

Jenis penelitian yang digunakan dalam penelitian ini adalah jenis penelitian secara Yuridis Empiris, mengingat penelitian ini menggunakan data-data / fakta-fakta yang ada dilapangan dan dikaji berdasarkan peraturan Perundang-undangan yang terkait dengan permasalahan yang diangkat (Soekanto, 2007). Dalam penelitian ini dipergunakan pendekatan perundang-undangan (statue approach), pendekatan konsep (conceptual approach), pendekatan analitis (analytical approach), dan pendekatan kasus (case approach). Sumber data dalam penelitian ini menggunakan data primer dan data sekunder. Data primer yakni Bahan-bahan hukum yang digunakan sifatnya mengikat yang berpusat pada peraturan perundang-undangan yang berlaku (Muhamad, 2004), meliputi: UU No 23 Tahun 2014 tentang Pemerintahan Daerah, UU No 23 Tahun 2006 tentang Administrasi Kependudukan, Peraturan Pemerintah No 38 Tahun 2007 tentang Pembagian Urusan Pemerintahan, 
Peraturan Pemerintah No 37 Tahun 2007 tentang Pelaksanaan UU No 23 Tahun 2006 tentang Administrasi Kependudukan, Perda Kabupaten Gianyar No 1 Tahun 2002 tentang Penyelenggaraan Pendaftaran Penduduk Dalam Rangka Sinduk di Kabupaten Gianyar, Keputusan Bupati Gianyar, No 108 Tahun 2002 tentang Pendaftaran Penduduk Pendatang di Kabupaten Gianyar. Data Sekunder yakni Bahan hukum yang memberikan penjelasan mengenai bahan-bahan hukum primer yaitu terutama yang digunakan dari pendapat ahli hukum, hasil penelitian hukum, hasil ilmiah dari kalangan hukum.

Teknik Pengumpulan data yang digunakan dalam penelitian ini adalah: Wawancara, Teknik Studi Dokumen, Observasi. Setelah semua data terkumpul, baik data lapangan maupun data pustaka kemudian diklasifikasikan secara kualitatif yaitu mengetahui kualitas kebenaran dari data yang diperoleh dan dianalisa berdasarkan teori-teori yang relevan. Dari analisa tersebut dapat ditarik suatu kesimpulan untuk menjawab permasalahan dan pada akhirnya hasil tersebut disajikan dalam bentuk skripsi secara deskriptif analisis.

\section{HASIL DAN PEMBAHASAN}

\section{Kewenangan Kabupaten Gianyar dalam Melakukan Penertiban Penduduk Pendatang}

Dalam pemahaman UUD NRI Tahun 1945 ini adalah ada dasar pengaturan penduduk dalam konteks ini penduduk pendatang. Dalam UU No 23 Tahun 2014 tentang Pemerintahan Daerah juga jelas diatur tentang Kependudukan yaitu dalam Pasal 12 Ayat (2) huruf F yang menyatakan bahwa "Dalam bidang Administrasi Kependudukan dan Pencatatan Sipil merupakan urusan wajib". Pengaturan Administrasi Kependudukan juga dapat dilihat dalam lampiran huruf L khususnya dalam bidang Administrasi Kependudukan dan Pencatatan Sipil, dimana kewenangan Kabupaten/Kota adalah pelayanan pendaftaran peduduk. Mendasarkan pada Pasal di atas dapat dipahami bahwa ada kewenangan dari Kabupaten Gianyar untuk mengatur administrasi kependudukan termasuk di dalamnya pengaturan penduduk pendatang. Selanjutnya secara materiil pengaturan penduduk pendatang juga dapat dilihat dalam UU No 23 Tahun 2006 tentang Administrasi Kependudukan. Dalam UU No 23 Tahun 2006, pengaturan mengenai penduduk terdapat dalam Pasal 1 angka 2 yang menyatakan: "Penduduk adalah Warga Negara Indonesia dan Orang Asing yang bertempat tinggal di Indonesia”.

1) Perpindahan, wajib didaftarkan kepada Kepala Desa/kelurahan setempat dalam jangka waktu selambat-lambatnya 14 (empat belas) hari kerja sejak tanggal kedatangan;

2) Kedatangan penduduk warga Negara asing / penduduk sementara yang diakibatkan perpindaan antar daerah dalam wilayah Negara Republik Indonesia wajib didaftarkan kepada Bupati dalam jangka waktu selambat- lambatnya 14 (empat belas) hari kerja sejak tanggal kedatangan;

3) Kedatangan penduduk sementara dari Negara lain wajib didaftarkan kepada Bupati dalam jangka selambat-lambatnya 14 (empat belas) hari kerja sejak tanggal kedatangan;

4) Pendaftaran yang melebihi jangka waktu sebagaimana dimaksud ayat (1), (2) dan (3) Pasal ini dapat dilaksanakan setelah mendapatkan persetujuan camat setempat bagi penduduk warga Negara Republik Indonesia dan Gubernur Kepala Daerah bagi penduduk warga Negara asing / penduduk sementara.

Pasal 12 mengatakan bahwa:

1) Pendaftaran kedatangan penduduk warga Negara Indonesia diterbitkan kartu keluarga dan dicatat dalam buku induk penduduk;

2) Pendaftaran kedatangan penduduk warga Negara asing diterbitkan surat keterangan pendaftaran penduduk dan kartu keluarga serta dicatat dalam buku induk penduduk.

Atas dasar Peraturan Daerah Kabupaten Gianyar No 1 Tahun 2002 tentang Penyelenggaraan Pendaftaran Penduduk dalam Rangka Simduk di Kabupaten Gianyar mempunyai wewenang mengatur tentang administrasi penduduk pendatang hal tersebut sesuai dengan hasil wawancara penulis dengan Bapak I Ketut Swastika Camat Gianyar pada tanggal 23 Mei 2018 beliau mengatakan bahwa Kabupaten Gianyar mempunyai kewenangan didalam melakukan tertib administrasi terhadap penduduk pendatang di kabupaten Gianyar hal ini dapat dilihat dari ketentuan dalam Peraturan Daerah Kabupaten Gianyar No 1 Tahun 2002 dalam Pasal 2 setiap perpindahan penduduk, pendudukan sementara dan penduduk musiman wajib didaftarkan kepada Kepala Desa/Kelurahan setempat dengan melampirkan persyaratan seperti: surat pengantar dari kepala dusun/lingkungan, 
surat keterangan pindah, surat keterangan berkelakuan baik dari kepolisian, pasport dari penduduk wni yang baru datang dari luar negeri Berita acara pembebasan tahanan dari Kepala lembaga pemasyarakatan bagi penduduk WNI yang baru keluar dari lembaga pemasyarakatan (LP). Dengan dipenuhinya kelengkapan tersebut penduduk/warga tersebut telah dapat diberikan Kartu Identitas Penduduk Sementara (KIPS) / Surat Tanda Pendaftaran Penduduk Tinggal Sementara (STPPTS), selanjutnya dapat dilayani administrasi kependudukan secara legalitas.

\section{Sanksi Hukum terhadap Penduduk Pendatang yang Melanggar Administrasi Kependudukan}

Sistem aturan pemerintahan desa berasal dari peraturan perundang-undangan yang lebih tinggi ditambah dengan aturan-aturan tambahan sesuai dengan kondisi desa yang bersangkutan, sedangkan Desa Adat adalah satu kesatuan wilayah dimana warganya bersama-sama mengaktifkan diri dalam upacara-upacara keagamaan untuk pemeliharaan kesucian desa. Desa dengan pengertian ini disebut Desa Adat. Rasa kesatuan sebagai desa adat terikat oleh adanya faktor-faktor karang desa (pekarangan/wilayah dimana para warganya tinggal), awig-awig (suatu sistem aturan desa dengan perangkat pelaksanaannya), dan Kahyangan Tiga (tiga pura tempat persembahyangan bagi para warga desa, yaitu Pura Desa, Pura Puseh, dan Pura Dalem). Pura inilah menjadi ciri adanya suatu desa adat (Astika, 1986).

Dalam rangka pembaharuan hukum pidana, kiranya perlu diperhatikan beberapa masalah adat yang masih berlaku dan hidup dalam masyarakat baik yang tercantum dalam awig-awig desa adat maupun dalam catur agama (Putri et al., 2019) yaitu: Adi Agama, Kutara Agama, Purwa Agama dan Agama. Masalah adat tentang harta benda yang diatur dalam awig-awig desa adat, secara garis besarnya dapat dikelompokkan dalam tiga kelompok yaitu :

- Masalah pencurian

- Masalah pencurian benda suci

- Masalah merusak benda suci.

Pelanggaran adat ini misalnya lalai dan tidak melakukan kegiatan sebagai warga / krama desa adat, seperti tidak melaksanakan kewajiban "ayahan" desa, tidak hadir dalam rapat ("paruman") desa, tidak memenuhi kewajiban membayar iuran ("pepeson") untuk kepentingan upacara / pembangunan dan lain-lain. Masalah adat ini sifatnya ringan, oleh karena itu biasanya dikenakan sanksi denda yang besarnya sesuai dengan awig-awig yang berlaku di desa adat yang bersangkutan dan tidak melalui proses peradilan.

Stuktur kepengurusan desa adat di Bali pada masa kini bervariasi atas dua pola yaitu: Pola pimpinan tunggal, dimana pucuk pemerintahannya di pegang oleh satu orang yang umumnya di desa disebut Kelihan Desa/Bendesa Adat. Pola ini terdapat di Desa Bali Dataran (Luh, 1987). Kemudian, pola pimpinan mejemuk, dimana pimpinan desa adat dipegang oleh banyak orang. Pola ini terdapat di Desa Bali Aga. Masyarakat akan dapat melaksanakan dengan baik apabila putusan itu diambil berdasarkan awig-awig desa adat dan dilandasi oleh musyawarah mufakat.

Dengan demikian paruman desa pakraman dalam penertiban penduduk pendatang adalah mensosialisasikan kepada penduduk pendatang agar mereka yang hidup di lingkungan desa pakraman taat dan tunduk pada awig desa sehingga tidak terganggunya desa pakraman baik menyangkut masalah parhyangan, pawongan dan palemahan (Artajaya, 2017). dan bila hal ini dilanggar maka desa pakraman akan melakukan suatu reaksi adat berupa sanksi-sanksi adat yang dijatuhkan kepada mereka. Dalam hal palemahan Kelian Adat/Bendesa Adat harus mampu memberikan petunjuk kepada penduduk pendatang misalnya dalam hal membangun rumah hendaknya sesuai dengan konsep ulu teben (depan belakang), memakai tembok penyengker, dan lain-lain. Begitu juga dalam hal pawongan telah dilakukan pembinaan kebersihan, pecalang mengadakan rahasia KTP / Kipem, menyarankan membuat KTP / Kipem bagi yang belum memiliki.

Sesuai dengan wawancara penulis dengan Bapak I Ketut Swastika, Camat Gianyar, pada tanggal 23 Mei 2018 beliau mengatakan bahwa sanksi administratif bagi penduduk pendatang yang tidak membuat KTP/Kipem lebih dari 3 bulan yakni tidak akan diberikan pelayanan administrasi untuk selamanya sehingga yang bersangkutan tidak bisa tinggal tetap maupun sementara di wilayah Kabupaten Gianyar. Sanksi pidana sampai saat ini belum pernah ada diterapkan selama ini. 


\section{SIMPULAN DAN SARAN}

\section{Simpulan}

Berdasarkan uraian diatas, dapat disimpulkan bahwa Kabupaten Gianyar mempunyai kewenangan didalam melakukan tertib administrasi terhadap penduduk pendatang di kabupaten Gianyar hal ini dapat dilihat dari ketentuan dalam Peraturan Daerah Kabupaten Gianyar No 1 Tahun 2002 dalam Pasal 2 setiap perpindahan penduduk, pendudukan sementara dan penduduk musiman wajib didaftarkan kepada Kepala Desa/Kelurahan setempat. Kemudian, sanksi administratif yang diberikan kepada penduduk pendatang yang tidak membuat KTP/Kipem lebih dari 3 bulan tidak diberikan pelayanan administrasi untuk selamanya sehingga yang bersangkutan tidak bisa tinggal tetap maupun sementara di wilayah Kabupaten Gianyar.

\section{Saran}

Sesuai dengan kesimpulan tersebut diatas, ada pula beberapa saran yang hendak disampaikan yakini: kepada aparat pemerintah terbawah mulai dari Kepala Dusun/Lingkungan, Kepala Desa/Lurah dan Kecamatan hendaknya lebih sering mengadakan sidak diwilayahnya untuk mengetahui keberadaan penduduk pendatang dan jika ada penduduk pendatang yang belum memenuhi persyaratan hendaknya diberi sanksi yang tegas untuk adanya efek jera. Kemudian, kepada masyarakat utamanya yang menerima penduduk pendatang hendaknya segera melaporkan dan mendaftarkan penduduk pendatang yang tinggal di rumah / di wilayah masyarakat itu sendiri sehingga tertib administrasi kependudukan dapat terwujud.

\section{DAFTAR PUSTAKA}

Artajaya, I. W. E. (2017). Eksistensi Awig-Awig terhadap Penduduk Pendatang di Desa Pakraman Tegallalang. Jurnal Advokasi FH UNMAS, 7(2), 257-265.

Astika, S. (1986). Peranan Banjar Kepada Masyarakat Bali (cet. I). Dep. Bud.

Larantika, A. A. A. D. (2017). Peran Desa Adat dalam Penertiban Penduduk Pendatang di Kota Denpasar. Jurnal Dialektika, 2(1), 167-177.

Luh, S. N. (1987). Sistem Kepemimpinan Masyarakat Pedesaan Daerah Bali (Cet. I). Dep. Bud.

Lumi, H. (2015). Peranan Pemerintah dalam Pencegahan dan Penanggulangan Konflik Antar Kelompok (Suatu Study di Kelurahan Teling Atas Kecamatan Wanea Kota Manado). Jurnal Politico, 4(1), 1-11.

Muhamad, A. (2004). Hukum dan Penelitian Hukum. PT. Citra Aditya Bakti.

Prayuginingsih, H., Santosa, T. H., \& Arifin, S. (2011). Pengaruh Motivasi dan Kepuasan Kerja terhadap Kinerja Buruh Wanita di Gudang Tembakau Tempu Reja Kecamatan Pakusari Kabupaten Jember. AGRITECH, 13(1), 27-45.

Putri, K. A. M. P., Puspitasari, N. W. F., Dewi, N. K. K., Ekarini, N. W., Dewi, I. A. P. P., \& Mertadana, D. P. K. (2019). Pengaruh Hukum Adat Atau Awig-Awig terhadap Pengelolaan Dana Desa di Desa Banjar Kecamatan Banjar Kabupaten Buleleng Provinsi Bali. Jurnal Ilmiah Akuntansi Dan Humanika, 8(1), 1-13.

Soekanto, S. (2007). Pengantar Penelitian Hukum. UI Press. 